\title{
Family Medicine Patients' Use of the Internet for Health Information: A MetroNet Study
}

\author{
Kendra L. Schwartz, MD, MSPH, Thomas Roe, MD, Justin Northrup, MPT, \\ James Meza, MD, Raouf Seifeldin, MD, and Anne Victoria Neale, PhD, MPH
}

We explored a diverse sample of family medicine patients' use of the internet for health information. Primary objectives were to determine the extent of access to the Internet, and among those with access, the types of health information sought; how they search for that information; and how they assess the accuracy of the information. We also surveyed the physicians' perceptions of their patients' use of the Internet for health information. Of 1289 patients participating, 65\% reported access to the internet; age, sex, race, education, and income were each significantly associated with internet access. A total of $\mathbf{7 4 \%}$ of those with access had used the Internet to find health information for themselves or family members. Disease-specific information was most frequently sought, followed by medication information, and then information about nutrition and exercise. Patients determine website accuracy by the endorsement of the site by a government agency or a professional organization, their own perception of reliability of the website source, and the understandability of the information. Almost $90 \%$ attempted to verify the information they obtained. A majority had discussed website information with their physicians. The physicians $(n=92)$ underestimate the proportion of their patients who used the Internet for health information. A total of $36 \%$ of physicians said at least one patient per week brought in Internet health information, and $63 \%$ said they had suggested a specific website to their patients. Physicians need critical appraisal skills to determine whether information found by a patient is relevant to that patient's condition and is based on the best available evidence. In addition, physicians directing patients to websites for health information must be confident that the site is maintained and updated by a reliable and credible source. (J Am Board Fam Med 2006;19:39-45.)

Increasingly, patients are finding health-related information on internet sites. ${ }^{1-3}$ The Pew Internet and American Life Project ${ }^{4}$ estimated that on a typical day in 2004, 70 million Americans went on-line and 7 million looked for health or medical information. They also estimated that $85 \%$ of online women and $75 \%$ of on-line men had searched for health information at least once in the past. As

Submitted 1 July 2005; revised 29 November 2005; accepted 30 November 2005.

From the Department of Family Medicine, Wayne State University School of Medicine Detroit, MI 48201 (KLS, TR, JN, AVN); Department of Family Medicine, Henry Ford Health Systems, Detroit, MI 48202 (JM); and Department of Family Medicine, North Oakland Medical Centers, Pontiac, MI 48341 (RS).

Funding: This study was funded by grants from the Michigan Consortium for Family Practice Research, and Department of Health and Human Services Health Resources and Services Administration (D12 HP00175).

Conflict of interest: none declared.

Corresponding author: Kendra L. Schwartz, MD, MSPH, Department of Family Medicine, 101 E. Alexandrine, Wayne State University School of Medicine, Detroit, MI 48201 (E-mail: kensch@med.wayne.edu). more people gain access to the internet, particularly with high-speed connections, the numbers seeking healthcare information for themselves or their family members will likely increase.

A number of studies have reported that the availability of internet-based health information to nonhealth professional consumers has influenced patient knowledge and expectations regarding healthcare, as well as the patient-physician relationship. Jadad et $\mathrm{al}^{5}$ found that over $90 \%$ of a sample of cancer-care providers (30 physicians and 37 nurses) reported that patients had brought information from the internet to them for discussion.

Murray et $\mathrm{al}^{6}$ conducted a nationally representative telephone survey of 3209 people: $31 \%$ had looked for health information on the internet in the past year; $16 \%$ had found health information relevant to themselves; and $8 \%$ had taken information to their physician. Although socio-economic factors were associated with looking for health information, it was not related to use of the information. A majority of people who took information to their 
physician wanted an opinion rather than a specific intervention. But, some qualitative studies ${ }^{7,8}$ and a national survey of United States physicians ${ }^{9}$ found that physicians are often not receptive to discussing internet information brought to a visit by their patients, sometimes leading to poorer doctor-patient communication ${ }^{9}$ or even open hostility. ${ }^{7}$

The most comprehensive source of information about use of the internet for health information is from the Pew Internet and American Life Project (www.pewinternet.org). This large populationbased telephone survey used a random digit sample of telephone numbers to identify potential participants to estimate the number of Americans who engage in Internet activities. There is also a burgeoning body of literature exploring patient use of the Internet for healthcare information. Most of these focused on disease-specific issues or special populations, such as cancer patients, ${ }^{10-12}$ surgery patients, ${ }^{13-15}$ gastroenterology clinic patients, ${ }^{16}$ rheumatology clinic patients, ${ }^{17}$ otolaryngology out-patients, ${ }^{18}$ glaucoma patients, ${ }^{19}$ and fertility clinic patients, ${ }^{20}$ among others. Few have looked at these issues with respect to a diverse, primary care population. $^{21-23}$

We were interested in exploring family medicine patients' use of the Internet for health information. Specifically, we wanted to determine the types of health information sought by patients, how they search for that information, and how they assess the accuracy of the information. Our study was conducted in 2 phases. In the first phase, the primary objective was to determine the level of access to the Internet and the subsequent Internet health activities and interests of a large, diverse sample of family medicine patients. In the second phase, the objective was to survey the physicians that provided care in clinical sites from which the patients were recruited about their perceptions of their patients' use of the Internet for health information.

\section{Methods}

\section{Patient Survey}

Patients age 18 years or older were recruited for this cross-sectional study from the waiting rooms of 13 primary care offices affiliated with the MetroNet practice-based research network (PBRN) in the metropolitan Detroit area. Each office was asked to recruit at least 100 consecutive adult patients. A PBRN staff member assisted with recruit- ing until the process was routine for the office staff. Data collection commenced in a staggered schedule from October 2002 through March 2003, so that a proportion of the total offices were collecting data at the same time. The study was approved by WSU Human Investigation Committee and the respective Institutional Review Boards of the participating practices.

Individuals who agreed to participate were asked to complete a questionnaire that included a demographic section and 13 questions inquiring about their Internet access, the type of health-related information they had sought on the Internet (if any), their search strategies, their assessment of the quality of the information obtained, and any discussions they may have had about Internet sources of health information with their healthcare provider.

\section{Physician Survey}

In mid-2003, during a MetroNet member meeting, shortly after the conclusion of the patient data collection, PBRN physicians suggested a survey of the clinicians who practiced at the participating sites to determine their impressions of their patients' use of the Internet for health information. The patient survey instrument was modified to ask physicians similar questions to those that had been asked of the patients. For instance, patients had been asked "Do you use the internet for health information?"; physicians were asked "What percentage of your patients use the internet for health information?" Physicians at all 13 participating MetroNet sites were asked to complete the questionnaire over the time period of December 2003 to April 2004. Results of the patient survey were not given to the physicians until after all physicians had completed the survey.

\section{Data Analysis}

To ensure accuracy, the data were entered independently by 2 assistants, and differences were resolved by referring to the questionnaires. The data were first summarized with frequency distributions. Proportions were generated for demographic characteristics and the categorical survey questions of the patient and physician surveys. The descriptive characteristics of respondents and non-respondents were compared with $\chi^{2}$ tests or the Student $t$ test as appropriate. 
We generated a multivariable logistic regression model to determine the independent contribution of patient demographic predictors of internet access. The 5 demographic variables (age, race, gender, income, and education) were significantly associated with Internet access in the bivariate analyses, and all were entered in the regression model in descending order of their association with the dependent variable. Predictors were retained when the model $\chi^{2}$ statistic improved significantly $(P<.05)$. Interactions were examined as variables were added to the model. The model was generated with SPSS version 11.5 using the blockwise (hierarchical) entry method.

\section{Results}

\section{Patient Survey}

Of 1392 family medicine patients invited into the study, 1289 (93\%) agreed to participate. Similar numbers of participants were recruited from each of the 13 sites (range 97 to 128 patients per office). Non-respondents were more likely to be men and older in age than respondents (Table 1); there was no difference in race/ethnicity. The mean age of respondents was 42.9 years (SD 14.4; range 18 to 88 ), which was significantly younger than the average 50.2 years (SD 50.2) of the non-respondents. Of the respondents, $65 \%$ were female; $52 \%$ selfidentified as white, and $38 \%$ as African American. Respondents were fairly well educated: $63 \%$ had some education beyond high school. The income level of respondents had a rectangular distribution with at least $14 \%$ in each of the 5 income brackets.

\section{Internet Access}

Of the 1289 patients who participated in the study, $844(65 \%)$ reported access to the Internet and 622

Table 1. Demographic Characteristics of Patient Survey Respondents and Non-respondents

\begin{tabular}{|c|c|c|c|}
\hline Characteristic & Respondents N (\%) & Non-respondents N (\%) & $P$ Value* \\
\hline Sex & & & .063 \\
\hline Male & $441(34.2)$ & $44(42.7)$ & \\
\hline Female & $805(62.5)$ & $57(55.3)$ & \\
\hline Missing & $43(3.3)$ & $2(2.0)$ & \\
\hline Age & & & $<.001$ \\
\hline$<40$ years & $555(43.1)$ & $27(26.2)$ & \\
\hline 40-64 years & $568(44.1)$ & $44(42.7)$ & \\
\hline$\geq 65$ years & $106(8.2)$ & $22(21.4)$ & \\
\hline Missing & $60(4.6)$ & $10(9.7)$ & \\
\hline Race/ethnicity & & & .802 \\
\hline African American & $470(36.4)$ & $41(39.8)$ & \\
\hline White & $641(49.7)$ & $49(47.6)$ & \\
\hline Other $†$ & $123(9.5)$ & $9(8.7)$ & \\
\hline Missing & $55(4.3)$ & $4(3.9)$ & \\
\hline Education & & Not collected & \\
\hline Less than high school & $121(9.4)$ & & \\
\hline High school graduate & $325(25.2)$ & & \\
\hline Some college & $521(40.4)$ & & \\
\hline Bachelor's degree & $143(11.1)$ & & \\
\hline More than Bachelor's degree & $102(7.9)$ & & \\
\hline Missing & $77(6.0)$ & & \\
\hline Income & & Not collected & \\
\hline$<\$ 15,000$ & $231(17.9)$ & & \\
\hline$\$ 15,000-\$ 24,999$ & $153(11.9)$ & & \\
\hline$\$ 25,000-\$ 39,999$ & $223(17.3)$ & & \\
\hline$\$ 40,000-\$ 69,999$ & $272(21.1)$ & & \\
\hline$\geq \$ 70,000$ & $234(18.2)$ & & \\
\hline Missing & $176(13.7)$ & & \\
\hline
\end{tabular}

${ }^{*} \chi^{2}$ test used to compare proportions of given variables between respondents and non-respondents, except age, which used Student's $t$ test for comparison of means.

† Other category includes: Hispanic (35.6\%), Asian/Pacific Islander (17.4\%), Native American (12.9\%), unspecified other (34.1\%). 
(48\% of all participants/74\% of participants reporting Internet access) had used the Internet to find information for themselves or family members regarding health issues or medical conditions. Age, sex, race, education, and income were each significantly associated with Internet access.

A regression model was constructed to determine the independent contribution of the demographic variables for Internet access. All 5 demographic variables were significant predictors of Internet access (Table 2). After adjusting for all the other demographic variables in the model, older male patients were less likely to have Internet access. White patients were 2 times more likely than African American patients to report Internet access. Patients with the highest education level were 7 times more likely to have Internet access than those in the lowest education group. Similarly, patients at the highest income level were nearly 5 times more likely to have access than those in the lowest income range.

We also explored a multivariate model to predict the use of the Internet to seek health information. However, because $74 \%$ of those with Internet access had reported searching for health information, there were too few negative responders for the

Table 2. Demographic Predictors of Internet Access

\begin{tabular}{lcc}
\hline Demographic Variable & $\begin{array}{c}\text { Unadjusted } \\
\text { OR }\end{array}$ & $\begin{array}{c}\text { Adjusted* OR } \\
(95 \% \mathrm{CI})\end{array}$ \\
\hline $\begin{array}{l}\text { Male } \\
\text { Age }\end{array}$ & 0.94 & $0.70(0.50,0.97)$ \\
$\quad<40$ years & 7.57 & $5.67(3.10,10.36)$ \\
40 to 64 years & 3.78 & $2.95(1.63,5.35)$ \\
$\quad \geq 65$ years & Reference & \\
Race/ethnicity & & \\
$\quad$ White & 2.16 & $1.97(1.42,2.72)$ \\
Other & 0.96 & $1.25(0.72,2.18)$ \\
$\quad$ Black & Reference & \\
Education & & \\
Less than or equal to & Reference & \\
$\quad$ high school & & \\
Some college & 4.80 & $3.88(2.80,5.37)$ \\
More than or equal to & 10.82 & $7.24(4.36,12.03)$ \\
$\quad$ Bachelor's degree & & \\
Income & & \\
$<\$ 25,000$ & Reference & \\
\$25,000-\$69,999 & 3.25 & $2.21(1.57,3.10)$ \\
$\geq \$ 70,000$ & 10.40 & $4.80(2.84,8.11)$ \\
\hline Each demographic variable was adjusted for all the other de- \\
mographic variables.
\end{tabular}

model to determine significant predictors of searching for health information.

\section{Types of Health Information Sought}

The questionnaire asked about the types of health information for which internet users searched ( $\mathrm{Ta}$ ble 3). Because the respondents were instructed to check all options that apply, and patients often used the Internet for more than one category of information, the sum of the frequencies of responses is greater than the number of Internet health information seekers. Disease-specific information was most frequently sought, followed by medication information, and then information about nutrition and exercise.

\section{Internet Search Strategies}

When queried about their strategies for searching for health information, $82.5 \%$ of respondents said that they use "key words" with search engines (eg, www.Google.com). One third (33.7\%) said they enter general health-related sites (eg, www. WebMD.com), and fewer (12.5\%) directly access a specific health information website. Again, responses were not mutually exclusive as participants were asked to indicate all their search strategies.

\section{Evaluation of Internet Health Information}

Almost all respondents in our sample reported the internet information they obtained was under-

Table 3. Patient Internet Searches by Type of Healthrelated Topic, and Number of Health-related Topics Searched per Respondent $(\mathrm{N}=622)$

\begin{tabular}{lrc}
\hline & $\mathrm{N}$ & $\%$ \\
\hline Health topics searched on-line & & \\
Specific disease or condition & 493 & 79 \\
Medications & 332 & 53 \\
Nutrition and exercise & 300 & 48 \\
Healthcare providers & 220 & 35 \\
Illness prevention & 211 & 34 \\
Alternative therapies & 153 & 25 \\
Other & 7 & 1 \\
Missing & 3 & 0.5 \\
Number of above health-related topics searched & & \\
One category & 151 & 24 \\
Two categories & 149 & 24 \\
Three categories & 137 & 22 \\
Four or more categories & 182 & 29 \\
No category & 3 & 0.5 \\
\hline
\end{tabular}


standable (98.7\%) and trustworthy (98.1\%). Two survey questions addressed specific factors that might influence the perceived accuracy of webbased information, and how users verify the health information obtained from such Internet sources. Determining the level of accuracy of a particular website was based on a number of factors (Table 4). Among the most important factors was the apparent endorsement of the site by a government agency or a professional organization, the users' perception of reliability of the website source, and the understandability of the information. Almost 90\% reported attempting to verify the information they obtained (Table 4). A majority of these respondents $(61 \%)$ said they used multiple sources for verification.

\section{Discussing Internet Health Information}

Respondents who had reported using the internet to find health-related information $(\mathrm{N}=622)$ were queried about how often they had discussed this information with their physicians. Of the 605 responding to this question, $46(7.6 \%)$ reported "almost every visit," 318 (52.6\%) reported "sometimes," 176 (29.1\%) reported "never," and 65 $(10.7 \%)$ reported "don't recall." Finally the 844 subjects who reported access to the Internet were asked whether their healthcare provider had ever

Table 4. Factors Influencing the Perceived Accuracy of Healthcare Websites and Methods of Checking the Accuracy of Internet Health Information

\begin{tabular}{|c|c|c|}
\hline & $\mathrm{N}$ & $\%$ \\
\hline \multicolumn{3}{|l|}{$\begin{array}{l}\text { Factors influencing perceived accuracy of } \\
\text { healthcare web sites }(\mathrm{N}=615)\end{array}$} \\
\hline $\begin{array}{l}\text { Endorsement by a government agency or } \\
\text { professional organization }\end{array}$ & 296 & 48 \\
\hline Reliable source/author & 289 & 47 \\
\hline Understandability of the information & 275 & 45 \\
\hline Site is updated frequently & 166 & 27 \\
\hline Layout and appearance of the site & 74 & 12 \\
\hline Sponsored by a reputable drug company & 72 & 12 \\
\hline Medical advertising is on the site & 47 & 8 \\
\hline \multicolumn{3}{|l|}{$\begin{array}{l}\text { Methods of checking the accuracy of Internet } \\
\text { health information }(\mathrm{N}=614)\end{array}$} \\
\hline Discuss with healthcare provider & 334 & 54 \\
\hline Compare information from different sites & 295 & 48 \\
\hline $\begin{array}{l}\text { Compare with non-Internet sources (print } \\
\text { sources, TV, etc) }\end{array}$ & 247 & 40 \\
\hline Discuss with friends or family & 244 & 40 \\
\hline Never check the accuracy & 65 & 11 \\
\hline
\end{tabular}

suggested an Internet source for health information. Of the 809 who responded to this question, 72 (8.9\%) reported "yes"; 615 (76.0\%) reported "no"; and $122(15.1 \%)$ reported "don't recall."

\section{Physician Survey}

Ninety-two physicians from the same MetroNet offices participated in the physician survey. We had $100 \%$ participation from the sites with fewer than 5 physicians. For the larger sites, with 10 to 30 physicians (including residents), the response rate ranged from $70 \%$ to $95 \%$.

The mean age of the physicians who completed the survey was $38.5(\mathrm{SD}=9)$ years; $51 \%$ were male. The average number of years practicing as a licensed physician was $8.4(\mathrm{SD}=9)$ years. Approximately $40 \%$ of physicians said that the majority of their patients were African American; a similar percentage said that the majority of their patients were White. Physicians tended to underestimate the proportion of their patients who had access to the Internet: $63 \%$ thought that less than half of their patients had Internet access (whereas $65 \%$ of patients reported such access). Similarly, the majority of physicians $(81 \%)$ thought that less than half of their patients used the Internet for health information, whereas $74 \%$ of patients said they were using it for this purpose. Physicians correctly identified nutrition and exercise as among the top 4 health topics on which patients are most likely to conduct internet searches, although disease-specific and medication-specific information were the top $2 \mathrm{pa}-$ tient searching topics.

When physicians were asked how many of their patients discuss health information obtained from the Internet, $13.6 \%$ stated at least one patient per day, and $36.4 \%$ estimated at least one patient per week. Most physicians (88\%) thought their patients mostly or sometimes understood the information they obtained, and only $1 \%$ of physicians said that their patients rarely trusted the information. Sixtythree percent of physicians reported that they suggested a specific website to their patients.

\section{Discussion}

Of a large ethnically diverse sample of family medicine patients, $65 \%$ reported they had access to the Internet; this is a higher level of access than predicted by their physicians. Internet access was significantly associated with every measured demo- 
graphic variable. Education and income were positively associated; age was negatively associated with access. White patients were twice as likely to have Internet access compared with African Americans. Men were less likely than women to have access. These demographic associations with Internet use have been reported in several other studies and have been referred to as the "digital divide."2,24

We were unable to determine demographic variables associated with on-line health information seeking because most of our users (74\%) had sought such health information, leaving insufficient variance in this dependent variable for a multivariate model. However, our predictors for internet access are the same predictors of health information seeking reported by the Pew Internet and American Life Project. ${ }^{25}$ In that population-based telephone interview study, 66\% of US Internet users in 2002 to 2003 (the same time period of our survey) said they go on-line to look for health information.

Our study sample appears similar to those in the Pew Project ${ }^{4,25}$ in the health topics searched online, providing some confidence in the generalizability of the study findings. The most commonly searched topics reported by our respondents, in descending order, were specific disease or conditions, medications, nutrition and exercise, illness prevention, and alternative therapies. With the exception of illness prevention, these were also the most popular topics reported in the Pew Project.

Many of our patients reported trying to determine the accuracy of the healthcare websites that they visited, either by looking for government or professional organization endorsements or by their perception of author credentials. Other frequently used methods to determine credibility included patient understanding of the information, and efforts to compare information between websites. Eysenbach and Köhler ${ }^{26}$ found that focus group participants reported similar methods for assessing credibility. Finally, patients often discuss the Internet health information with their doctor.

The strengths of this study include the diverse patient sample, and the high response rate (93\%) from a large number of practices that are active in the MetroNet PBRN. Although the study surveyed a non-random convenience sample of family medicine patients, our findings appear similar to those reported by the Pew Internet and American Life Project $^{27}$ and others. ${ }^{2,24,26}$
A "patient-centered" approach to medical decision making has gained acceptance as the preferred approach in primary care. ${ }^{28}$ This method encourages both patients and physicians to participate in the treatment decision-making process. For the patient, this includes obtaining information, as well as disclosing preferences and weighing treatment alternatives. ${ }^{1}$ Patients increasingly obtain on-line medical information to discuss with their doctors, and the majority of physicians in our study said that their patients usually understand and trust the online information they bring in. However, physicians need critical appraisal skills to determine that the information found by a patient is relevant to that patient's condition and is based on the best available evidence. In addition, physicians directing patients to websites for health information must be confident that the site is maintained and updated by a reliable and credible source..$^{2,29-31}$ Training for patients to improve their critical appraisal skills or, at the least, ability to discern reputable sites is also needed.

Another implication for the future is the need to train physicians and medical students about discussing information brought to the office visit by their patients. Both qualitative $e^{7,8}$ and quantitative ${ }^{9}$ studies have reported that physicians can feel challenged by the patient who brings in Internet information, leading to degradation of the patient-physician relationship. With the growing number of tasks to be completed during an increasingly shorter office visit, physicians (or perhaps their staff) will need to quickly appraise the information for accuracy and relevancy to the patient's condition, and skillfully relate the information to the patient's care.

\section{References}

1. Gerber BS, Eiser AR. The patient-physician relationship in the internet age: future prospects and the research agenda. J Med Internet Res 2001;3:315.

2. Cotton SR, Gupta SS. Characteristics of online and offline health information seekers and factors that discriminate between them. Soc Sci Med 2004;59: 1795-806.

3. Kaiser Family Foundation. E-Health and the elderly: how seniors use the internet for health-Survey. Available from: www.kff.org/entmedia/7223.cfm. Accessed January 20, 2005.

4. The Pew Internet and American Life Project. Trends 2005. Internet: The mainstreaming of online 
life. Available from: http://pewresearch.org/trends/ trends2005-internet.pdf. Accessed May 14, 2005.

5. Jadad AR, Sigouin C, Cocking L, Booker L, Whelan T, Browman G. Internet use among physicians, nurses, and their patients. JAMA 2001;286:1451-2.

6. Murray E, Lo B, Pollack L, et al. The impact of health information on the internet on the physician-patient relationship. Arch Intern Med 2003;163:1727-34.

7. Broom A. Virtually He@lthy: the impact of internet use on disease experience and the doctor-patient relationship. Qual Health Res 2005;15:325-45.

8. Henwood F, Wyatt S, Hart A, Smith J. Ignorance is bliss sometimes: constraints on the emergence of the 'informed patient' in the changing landscapes of health information. Sociol Health Illn 2003;25:589607.

9. Murray E, Lo B, Pollack L, et al. The impact of health information on the internet on health care and the physician-patient relationship: national U.S. survey among 1,050 U.S. physicians. J Med Internet Res 2003;5:e17.

10. Pereira JL, Koski S, Hanson J, Bruera ED, Mackey JR. Internet usage among women with breast cancer: an exploratory study. Clin Breast Cancer 2000;1: $148-53$.

11. Ziebland S, Chapple A, Dumelow C, Evans J, Prinjha S, Rozmovits L. How the internet affects patients' experience of cancer: a qualitative study. BMJ 2004;328:564.

12. Unruh HK, Bowen DJ, Meischke H, Bus $\mathrm{N}$, Woldridge JA. Women's approaches to the use of new technology for cancer risk information. Women Health 2004;40:59-78.

13. Ikemba CM, Kozinetz CA, Feltes TF, et al. Internet use in families with children requiring cardiac surgery for congenital heart disease. Pediatrics 2002; 109:419-22.

14. Semere W, Karamanoukian HL, Levitt M, et al. A pediatric surgery study: parent usage of the Internet for medical information. J Pediatr Surg 2003;38: 560-4.

15. Murero M, D’Ancona G, Karamanoukian H. Use of the internet by patients before and after cardiac surgery: telephone survey. J Med Internet Res 2001; 3(3):e27.

16. O'Connor JB, Johanson FJ. Use of the web for medical information by a gastroenterology clinic population. JAMA 2000;284:1962-4.

17. Gordon M-M, Capell HA, Madhok R. The use of the internet as a resource for health information among patients attending a rheumatology clinic. Rheumatology 2002;41:1402-5.

18. Tassone P, Georgalas C, Patel NN, Appleby E, Kotecha B. Do otolaryngology out-patients use the internet prior to attending their appointment?. J Laryngol Otol 2004;118:34-8.

19. Hoevenaars JG, Schouten JS, van den Borne B, Beckers HJ, Webers CA. Knowledge base and preferred methods of obtaining knowledge of glaucoma patients. Eur J Ophthalmol 2005;15:32-40.

20. Weissman A, Gotlieb L, Ward S, Greenblatt E, Casper RF. Use of the internet by infertile couples. Fertil Steril 2000;73:1179-82.

21. Diaz JA, Griffith RA, Ng JJ, Reinert SE, Friedmann PD, Moulton AW. Patients' use of the Internet for medical information. J Gen Intern Med 2002;17: $180-5$.

22. Grover F, Wu D, Blanford C, Holcomb S, Tidler D. Computer-using patients want internet services from family physicians. J Fam Pract 2002;51:570-2.

23. Smith-Barbaro PA, Licciardone JC, Clarke HF, Coleridge ST. Factors associated with intended use of a Web site among family practice patients. J Med Internet Res 2001;3:e17.

24. Wong BM, Yung BM, Wong A, Chow CM, Abramson BL. Increasing internet use among cardiovascular patients: new opportunities for heart health promotion. Can J Cardiol 2005;21:349-54.

25. Fox S, Fallows D. Internet health resources: health searches and email have become more commonplace, but there is room for improvement in searches and overall Internet access. Pew Internet \& American Life Project: Online Report. Available from: www.pewinternet.org/reports/toc.asp?Report $=95$. Accessed July 1, 2005.

26. Eysenbach G, Köhler C. How do consumers search for and appraise health information on the world wide web? Qualitative study using focus groups, usability tests, and in-depth interviews. BMJ 2002;324: 573-7.

27. Fox S, Rainie L. Vital decisions: how internet users decide what information to trust when they or their loved ones are sick. Pew Internet \& American Life Project: Online Report. Available from: http://www.pewinternet.org/ pdfs/PIP_Vital_Decisions_May2002.pdf. Accessed July 1, 2005.

28. Stewart MA. Effective physician-patient communication and health outcomes: a review. CMAJ 1995; 152:1423-33.

29. Kunst H, Groot D, Latthe PM, Latthe M, Khan KS. Accuracy of information on apparently credible websites: survey of five common health topics. BMJ 2002;324:581-2.

30. Gagliardi A, Jadad AR. Examination of instruments used to rate quality of health information on the internet: chronicle of a voyage with an unclear destination. BMJ 2002;324:569-73.

31. Eysenbach G. Consumer health informatics. BMJ 2000;320:1713-6. 